\title{
B-cell hyperfunction in children with immune thrombocytopenic purpura persists after splenectomy
}

\author{
Paola Giordano', Simona Cascioli², Giuseppe Lassandro', Valentina Marcellini², Fabio Cardinale ${ }^{3}$, Federica Valente', \\ Franco Locatelli ${ }^{4,5}$ and Rita Carsetti2,
}

BACKGROUND: Immune thrombocytopenic purpura (ITP) is characterized by reduced platelet count secondary to immunemediated destruction, this results in an increased bleeding risk. Autoantibodies binding to platelets tag them for premature destruction in the spleen. For this reason, splenectomy is often performed as treatment of chronic forms of disease that are resistant to pharmacological therapy.

METHODS: We studied 30 patients with ITP and compared them with age-matched controls.

RESULTS: We show that B cells of patients with chronic ITP are intrinsically hyperreactive, producing more than normal lgG in vivo and plasma cells in vitro. In normal individuals after splenectomy, a significant depletion of memory B cells is observed, associated with loss of reactivity to $\mathrm{CpG}$ oligodeoxynucleotide and consequent inability to form antibody-producing cells. In Enzyme-Linked ImmunoSpot Methods, we compared three splenectomized ITP patients relapsing after surgery, 30 healthy controls, and 37 individuals splenectomized for trauma, spherocytosis, thalassemia, nonhematological tumor, and other diseases. CONCLUSIONS: We confirmed that B cells of ITP patients remain hyperreactive in vitro and form high numbers of antibody-producing cells after splenectomy. Thus, chronic ITP may be associated with intrinsic B-cell hyperfunction, leading to the production of antibodies with multiple specificities including that against platelets.

mmune thrombocytopenic purpura (ITP) is an acquired immune-mediated disorder characterized by isolated thrombocytopenia, defined as a peripheral blood platelet count below $100 \times 10^{9} / 1$, in the absence of any obvious initiating and/or underlying cause of thrombocytopenia. ITP is generally considered to be a benign disorder in children, with an incidence of 2 to 5 per 100,000 children younger than $15 \mathrm{y}(1)$. ITP is classified by duration as newly diagnosed (less than $3 \mathrm{mo}$ ), persistent (3-12-mo duration), and chronic (>12-mo duration) (2).

ITP in children is usually short lived with at least two-thirds of affected patients recovering spontaneously within $6 \mathrm{mo}$ (3).
Signs and symptoms vary widely. Many patients have either no symptoms or minimal bruising, whereas few others experience serious bleeding, which may include gastrointestinal or intracranial hemorrhage (4). The bleeding risk correlates to some extent, but not completely, with the severity of thrombocytopenia (5). Additional factors (e.g., age, lifestyle, uremia) affect the risk and should be evaluated before the appropriate management is determined $(6,7)$. Treatment is rarely indicated in patients with platelet counts above $50 \times 10^{9} / \mathrm{l}$ in the absence of the following conditions: bleeding, trauma, and surgery (8). Only $3 \%$ of children with ITP have clinically significant symptoms, such as severe epistaxis or gastrointestinal bleeding. Severe bleeding is more likely to occur in children with platelet counts less than $50 \times 10^{9} / 1$. The incidence of intracranial hemorrhage in children with ITP is $\sim 0.1-0.5 \%$ (9).

If treatment is necessary for acute ITP, the first-line/initial options are intravenous immunoglobulin (10) and corticosteroids (11). Treatment options for children with persistent/ chronic ITP include intravenous immunoglobulin and corticosteroids as first-line treatment, followed by rituximab, cyclosporine, azatioprine, and other immunosuppressive drugs. A number of studies with thrombopoietin-receptor agonists, which increase platelet production, have shown encouraging results in adults, but finalized studies are not yet available to support the use of these agents in children. Splenectomy is an effective treatment for pediatric ITP, although it carries the risk of sepsis that persists for life (12).

ITP is characterized by the production of autoantibodies that bind to platelets targeting them for phagocytosis by macrophages in the spleen (13) and liver (14). Consequently, the life span of platelets is shortened, and bone marrow production cannot compensate destruction. Other mechanisms, including T-cell-mediated cytotoxicity (15) and impaired platelet production, have also been demonstrated to cause ITP $(16,17)$.

The still incompletely defined pathophysiology of the disease contributes to explain why there is no "best treatment" for all patients $(16,18)$.

$B$ cells have been at the center of attention for many years, and rituximab, a humanized antibody binding to the B-cell

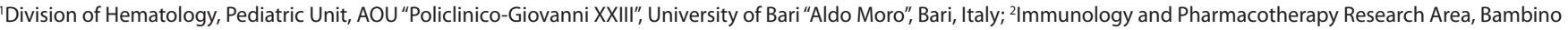
Gesù Children's Hospital IRCCS, Rome, Italy; ${ }^{3}$ Division of Pulmonology, Allergy, and Immunology, Pediatric Unit, AOU “Policlinico-Giovanni XXIII", Bari, Italy; ${ }^{4}$ Department of Oncohaematology, Bambino Gesù Children's Hospital IRCCS, Rome, Italy; ${ }^{5}$ Department of Pediatric Science, University of Pavia, Pavia, Italy; ${ }^{6}$ Department of Laboratories and Diagnostic Immunology Unit, Bambino Gesù Children's Hospital IRCCS, Rome, Italy. Correspondence: Paola Giordano (paola.giordano@uniba.it)

Received 8 April 2015; accepted 4 August 2015; advance online publication 2 December 2015. doi:10.1038/pr.2015.211
} 
$\mathrm{CD} 20$ antigen, has been used with the intention of removing autoreactive B-cell clones. Several studies, both in adults and in children, have shown a significant initial response in $40 \%$ of the cases and a long-lasting (5 y) response in 20-25\% (19). For patients relapsing after rituximab therapy, splenectomy is often the only choice to overcome disease. Recently, a very interesting study has investigated the reasons of rituximab failure in patients who had to be splenectomized after antibody treatment (20). The results demonstrated that rituximab depletes $\mathrm{CD} 20^{+} \mathrm{B}$ cells not only in peripheral blood but also in the spleen, where only $0.2-1 \%$ of $B$ cells survived most of which were memory $\mathrm{B}$ cells and plasma cells. These antibody-producing cells were shown to have the genetic signature of long-lived plasma cells and are not sensitive to anti-CD20 depletion. Despite rituximab removed CD20+ B cells but splenic long-lived plasma cells persisted so the clinical success was not achieved. Noteworthy that splenectomy after rituximab cured the disease in only 7 out of 10 patients suggesting that, in some cases, autoreactive B cells may also be generated elsewhere (21).

We have shown previously that, in patients with systemic lupus erythematosus, B cells able to produce autoantibodies are included in the memory B-cell pool, thus disease persistence or relapse may be caused by the periodical reactivation of these autoreactive memory B cells (22).

We studied the memory B-cell compartment and function in a cohort of pediatric ITP patients in order to identify a possible defect associated with the disease that could justify the pharmacological targeting of this cell type.

\section{RESULTS}

\section{B-cell Phenotype in Pediatric ITP Patients}

Peripheral blood mononuclear cell (PBMC) from pediatric ITP patients (described in Table 1) and healthy controls were stained with antibodies to CD19, CD24, CD27, CD38, IgM, and $\mathrm{IgD}$ and analyzed by flow cytometry in order to characterize B-cell subsets. The population of memory $\mathrm{B}$ cells can be identified as $\mathrm{CD} 19^{+} \mathrm{CD} 27^{+}$(Figure 1a, left) and includes IgM memory B cells, expressing IgM and IgD, and switched memory B cells, carrying Ig of other isotypes (Figure 1a, right). The percentages of total memory, switched and IgM memory $\mathrm{B}$ cells, were calculated in the B cell gate. As frequency and absolute number of memory B cells change with age, we compared ITP children with healthy controls of the same age. Four age-groups were created including a total of 131 healthy controls. There was no significant difference among the frequency of total memory, IgM, and switched memory B cells of patients and controls in any of the four age-groups analyzed (Figure 1b). Similarly, absolute numbers of memory B cells in patients were not different from the absolute numbers in the age-matched controls (Figure 1c).

\section{The Response to Toll-Like Receptor 9 Stimulation in the ITP Patients}

Toll-like receptor 9 (TLR9) is engaged by hypomethylated DNA (cytosine-phosphate-guanine (CpG)); we have previously demonstrated that in vitro TLR9 triggers memory B-cell
Table 1. Demographic and clinical characteristics of the ITP patients

\begin{tabular}{|c|c|c|c|c|c|}
\hline Name & $\begin{array}{l}\text { Age, } \\
\text { years }\end{array}$ & Sex & $\begin{array}{l}\text { Phases of } \\
\text { the disease }\end{array}$ & $\begin{array}{l}\text { Platelet count } \\
\left(\times 10^{9} /\right)^{\mathrm{a}}\end{array}$ & Therapy ${ }^{b}$ \\
\hline ITP1 & 9 & M & Newly & 100 & IVlg \\
\hline ITP2 & 2 & M & Newly & 67 & IVlg \\
\hline ITP3 & 3 & M & Newly & 119 & IVlg \\
\hline ITP4 & 7 & M & Newly & 95 & IVlg \\
\hline ITP5 & 12 & M & Newly & 73 & IVlg \\
\hline ITP6 & 12 & $\mathrm{~F}$ & Newly & 91 & IVlg \\
\hline ITP7 & 11 & M & Newly & 124 & IVIg \\
\hline ITP8 & 5 & M & Persistent & 102 & IVlg \\
\hline ITP9 & 2 & M & Persistent & 85 & None \\
\hline ITP10 & 9 & $\mathrm{~F}$ & Persistent & 50 & IVlg, CS \\
\hline ITP11 & 10 & $\mathrm{~F}$ & Chronic & 184 & IVlg \\
\hline ITP12 & 17 & $\mathrm{~F}$ & Chronic & 79 & IVlg \\
\hline ITP13 & 10 & M & Chronic & 18 & IVlg \\
\hline ITP14 & 12 & M & Chronic & 26 & $\begin{array}{l}\text { IVIg, CS, } \\
\text { RTX, CSA }\end{array}$ \\
\hline ITP15 & 16 & M & Chronic & 106 & IVlg \\
\hline ITP16 & 7 & $\mathrm{~F}$ & Chronic & 47 & IVlg, CS \\
\hline ITP17 & 9 & $\mathrm{~F}$ & Chronic & 65 & $\begin{array}{l}\text { IVIg, CS, } \\
\text { RTX }\end{array}$ \\
\hline ITP18 & 4 & $\mathrm{~F}$ & Chronic & 113 & IVlg, CS \\
\hline ITP19 & 13 & M & Chronic & 45 & IVlg, CS \\
\hline ITP20 & 9 & M & Chronic & 70 & IVlg, CS \\
\hline ITP21 & 6 & $\mathrm{~F}$ & Chronic & 123 & IVlg \\
\hline ITP22 & 3 & $\mathrm{~F}$ & Chronic & 115 & IVlg, CS \\
\hline ITP23 & 11 & $\mathrm{~F}$ & Chronic & 102 & IVlg, CS \\
\hline ITP24 & 8 & $F$ & Chronic & 300 & $\begin{array}{l}\text { IVlg, CS, } \\
\text { RTX }\end{array}$ \\
\hline ITP25 & 13 & $\mathrm{~F}$ & Chronic & 70 & IVlg, CS \\
\hline ITP26 & 13 & M & Chronic & 54 & none \\
\hline ITP27 & 14 & M & Chronic & 144 & $\begin{array}{l}\text { IVlg, CS, } \\
\text { RTX }\end{array}$ \\
\hline ITP28 & 12 & $\mathrm{~F}$ & Chronic & 22 & IVlg, CS \\
\hline ITP29 & 6 & M & Chronic & 54 & IVlg \\
\hline ITP30 & 10 & $M$ & Chronic & 48 & IVIg \\
\hline
\end{tabular}

CS, corticosteroid; CSA, cyclosporin A; F, female; IVIg, intravenous immunoglobulin; M, male; RTX, rituximab.

The platelet count at beginning of this study. ${ }^{\circ}$ The patients at time of enrolment had suspended drug treatment at least $14 \mathrm{~d}$ before entering the study.

proliferation and differentiation into antibody-producing cells $(23,24)$. Consequently, CpG stimulation can be used to measure the function and specificity of memory B cells. We have shown that in patients with systemic lupus erythematosus, autoantibodies can be detected in the supernatant of stimulated PBMC (22).

We asked the question whether PBMC from ITP patients respond to CpG and produce antiplatelet antibodies. In order to answer this question, PBMC from 30 healthy control and 30 ITP patients ( 7 newly diagnosed, 3 persistent, and 20 chronic) 
a

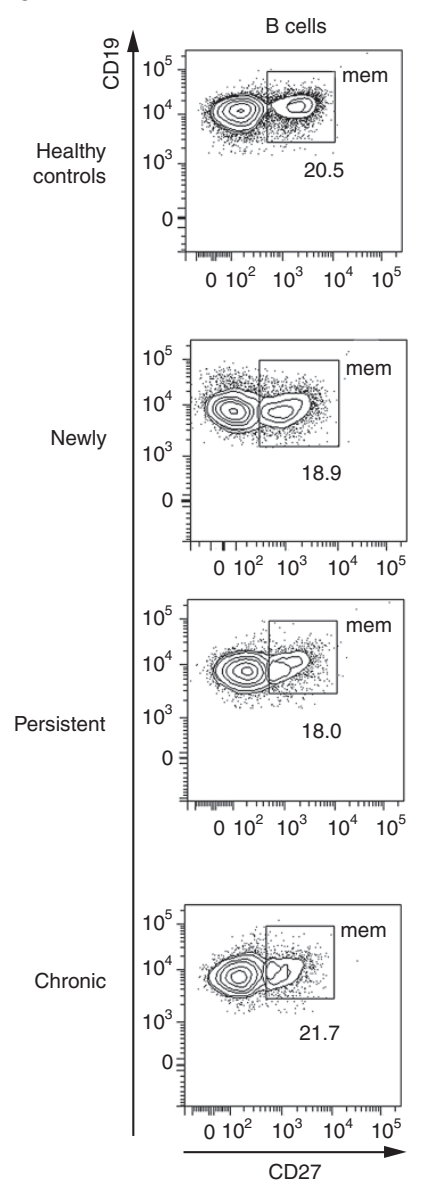

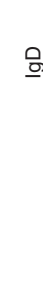

호․ $\begin{gathered}10^{5} \\ 10^{4} \\ 10^{3} \\ 0\end{gathered}$

Memory B cells

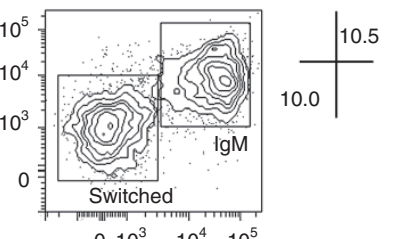

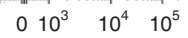

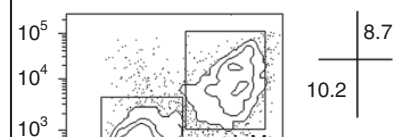

$10^{3}$
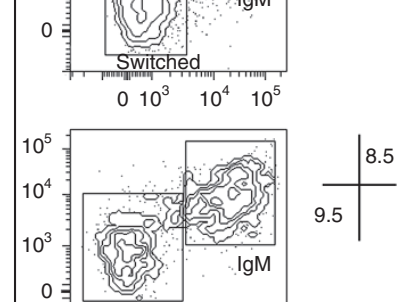

$$
0^{5}
$$

b

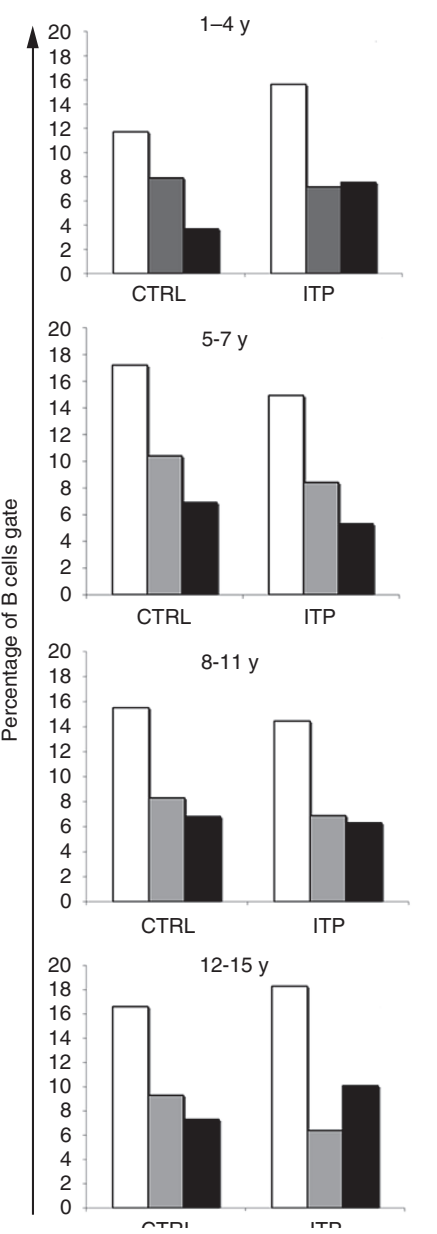

C
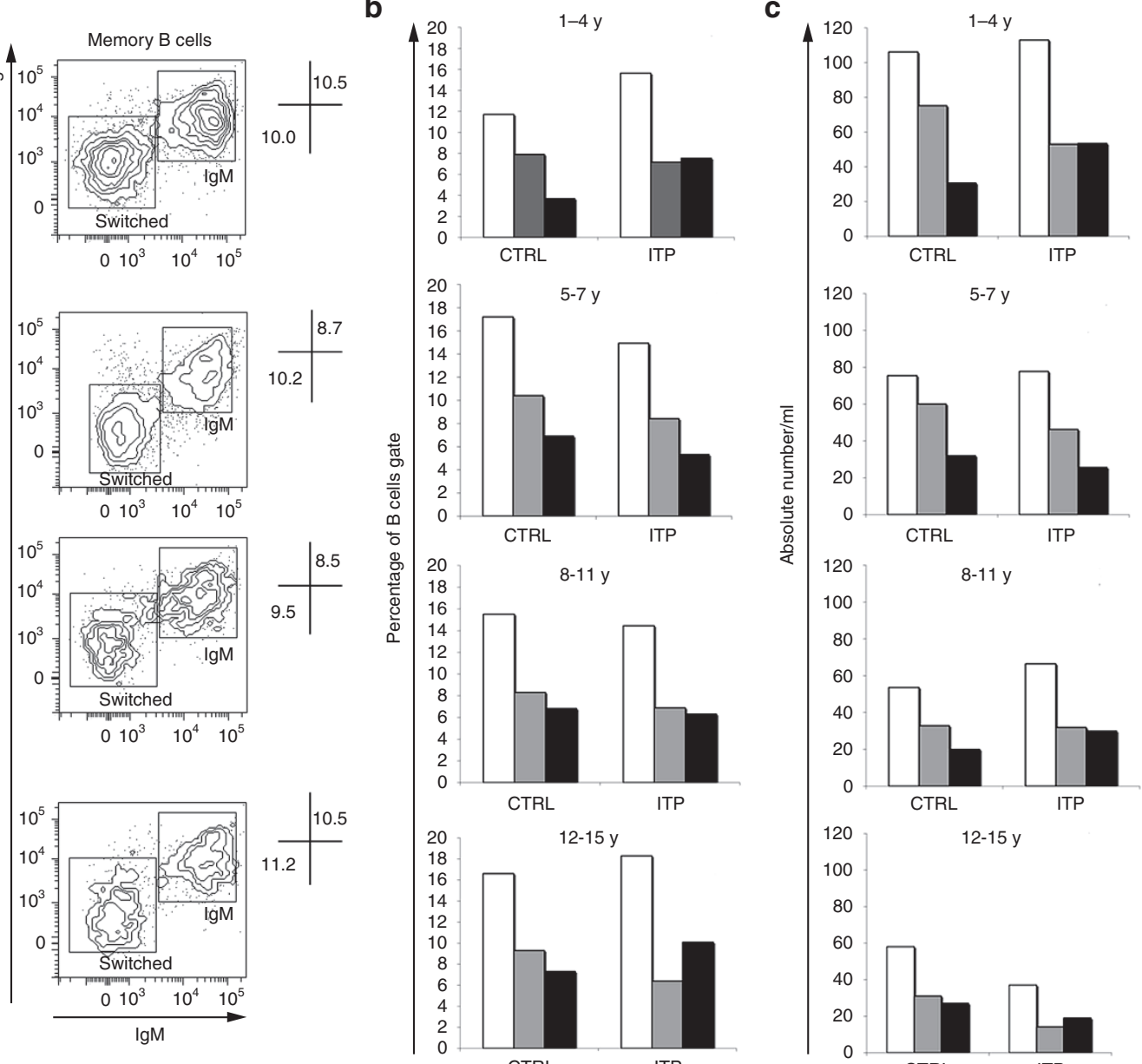

Figure 1. B-cell phenotype in ITP patients. (a) Contour plots show B cells from healthy controls and ITP patients. Memory B cells (mem) are identified as $\mathrm{CD} 19^{+} \mathrm{CD} 27^{+}$(B cells). In the gate of memory B cells, switched memory B cells (IgM and IgD) can be distinguished from IgM memory B cells (IgM ${ }^{+}$and $\left.\lg \mathrm{D}^{\text {dull }}\right)$. The numbers indicate the percentage of total memory (left plots), switched and lgM memory (right plots) in the B cell gate. (b) White columns represent the mean frequency of total memory B cells. The frequency of switched memory B cells is shown by the black columns and that of lgM memory B cells in gray. Values relative to healthy controls (CTRL, $n=129$ ) and ITP patients (ITP, $n=30$ ) are shown separately for the different age-groups indicated in the figure. (c) The histograms show the absolute numbers of B cell populations in each age-group of healthy controls $(n=131)$ and ITP $(n=30)$ patients. The numbers of controls in each age-group were: $1-4$ y $n=34 ; 5-7 y, n=29 ; 8-11$ y, $n=34 ; 12-15 y, n=34$. The size of B-cell populations was comparable among CTRL and ITP. Statistical significance was determined by the Student's $t$-test. ITP, immune thrombocytopenic purpura.

were stained with cell tracking reagent 5-chloromethylfluorescein diacetate and cultured with or without $\mathrm{CpG}$ for $7 \mathrm{~d}$. The samples were then stained with suitable combinations of antibodies against CD19, CD27, CD38, and IgM. In the B cell gate, the combination of $\mathrm{CD} 27$ and IgM identifies the following populations: $\mathrm{CD}^{27} \mathrm{IgM}^{+}$mature cells, $\mathrm{CD}^{2} 7^{+} \mathrm{IgM}{ }^{-}$switched memory, $\mathrm{CD}_{2} 7^{+} \mathrm{IgM}^{+}$IgM memory, $\mathrm{CD} 27^{\text {brigth }} \operatorname{IgM}^{-}$and $\mathrm{CD} 27^{\text {bright }} \operatorname{IgM}^{+}$ switched and IgM plasma cells, respectively. Whereas all healthy controls responded to $\mathrm{CpG}$ with proliferation (not shown) and plasma cell formation, lout of 3 of the ITP patient showed a reduced response (Figure 2a). Low responders were mostly newly diagnosed and persistent ITP cases, whereas the majority of chronic ITP patients were in the responder group (Figure 2b).

Next, we analyzed culture supernatants to assess immunoglobulin secretion. We found that, as expected, Ig were not spontaneously secreted (not shown), but after CpG stimulation, the production of antibodies of all isotypes was induced. In the supernatants of PBMC from ITP patients, the concentration of IgM and IgA was lower than in healthy controls, whereas IgG were increased in the chronic ITP group (Figure 2c). As patients with newly diagnosed and persistent ITP showed an impaired proliferative response to $\mathrm{CpG}$, a low antibody production was an expected result. Antiplatelet antibodies could not be measured in the supernatants probably due to insufficient sensitivity of our method of detection, which is normally used to measure antibodies in the serum where their concentration is at least 3 logs higher $(\mathrm{mg} / \mathrm{ml}$ instead of $\mu \mathrm{g} / \mathrm{ml})$.

Immunoglobulins in the supernatants derived from antibody-producing cells differentiated in vitro upon CpG stimulation. We compared the frequency of total B cells and plasma cells in the CpG cultures of controls (that all respond to CpG) with the frequency of the same populations in the group of ITP patients able to react to $\mathrm{CpG}$. This group, as already reported, was mostly composed of chronic ITP patients. We found that total B cells were lower than that in the controls $(P<0.0001)$, but plasma cells of both IgM and switched isotype were 
significantly increased (Figure 2d). Thus, chronic ITP patients show a reduced proliferative response to $\mathrm{CpG}$ (resulting in a low frequency of total B cells) associated with a significantly increased ability to terminally differentiate into plasma cells.

\section{Plasma Levels of Ig in ITP Patients}

In order to evaluate whether the higher ability to secrete antibodies in vitro could be demonstrated also in vivo, we compared the concentration of immunoglobulins in the plasma of ITP patients and 30 healthy controls. For patients treated with intravenous immunoglobulin, plasma was collected at least 1 mo after the last administration. We found that IgG levels were significantly increased compared with the controls (Figure 3a). In order to evaluate whether all antibodies were equally increased in the serum independent of their specificity, we measured antitetanus toxoid and antipneumococcal polysaccharide IgG (anti-PnPS). We found that these specificities were in the normal range (Figure 3b,c).

\section{Splenectomy Does Not Influence Antibody Production in ITP Patients}

Splenectomy is a largely employed treatment of chronic ITP of childhood when all other therapies, including rituximab, have failed. We analyzed PBMCs from three patients diagnosed a

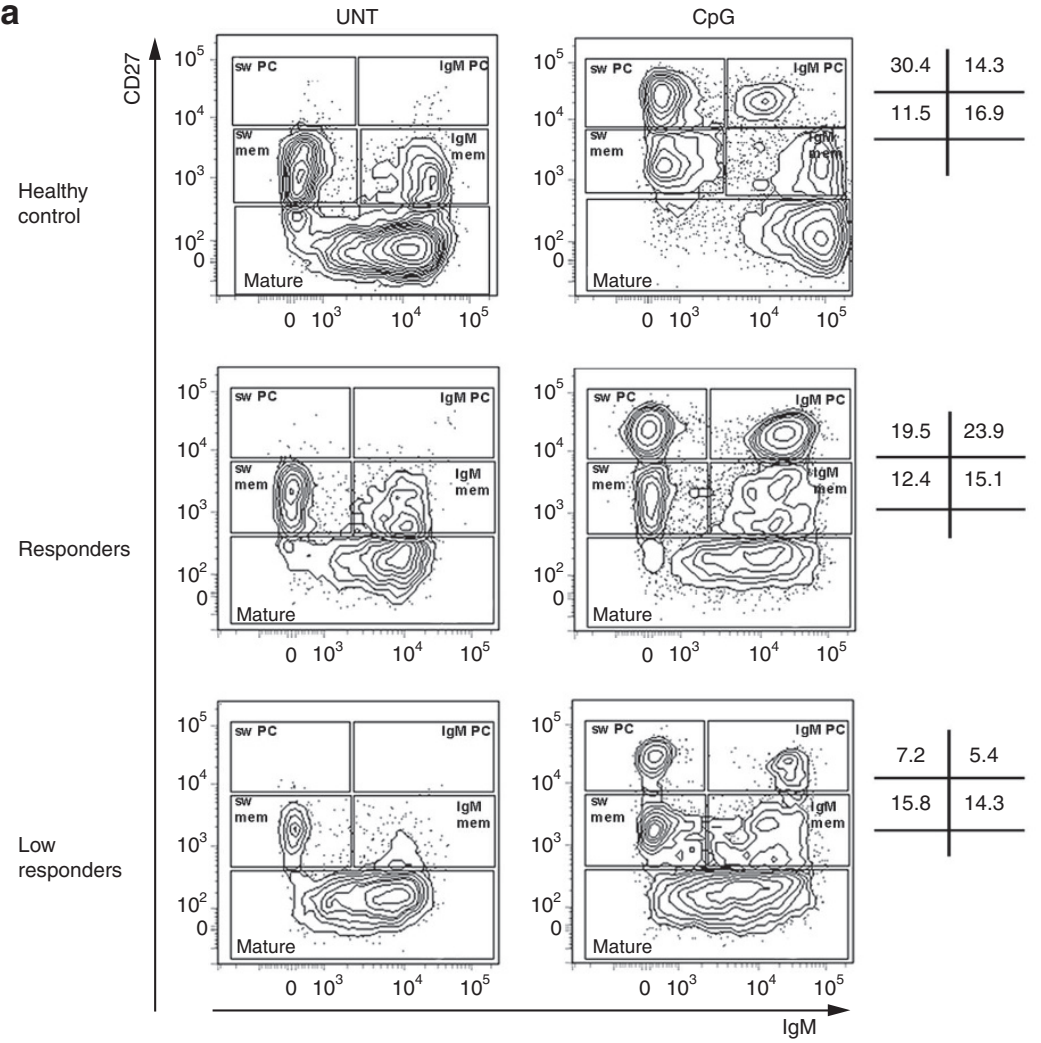

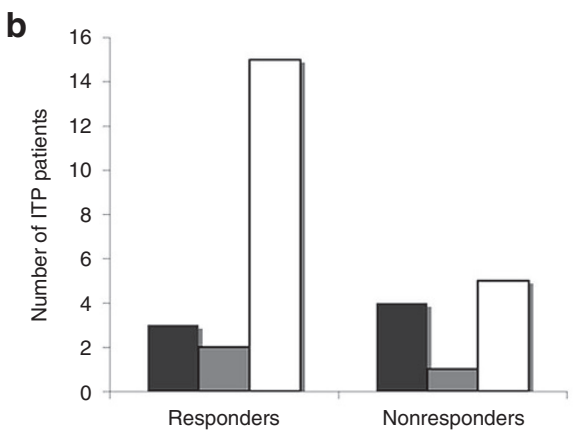

C

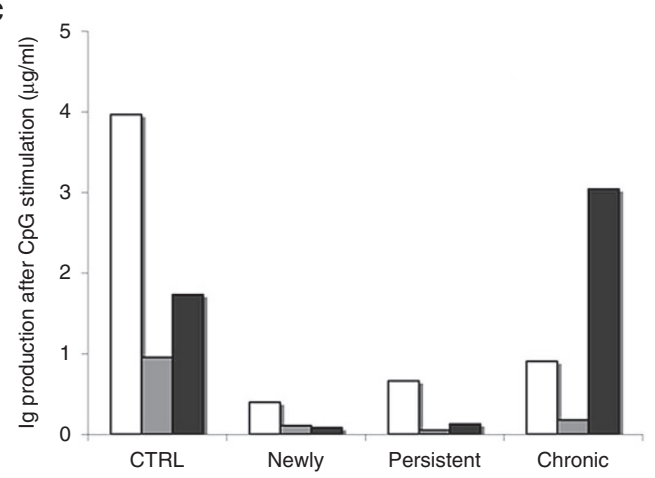

d

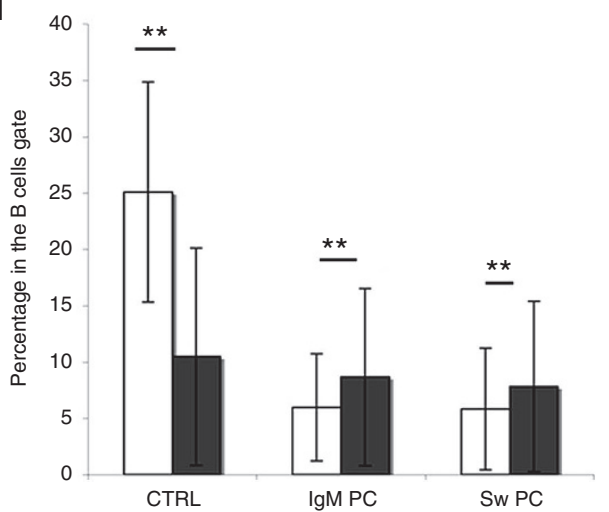

Figure 2. TLR-9 response in the ITP patients. (a) Contour plots show the staining of $B$ cells in the absence or presence of CpG. The gates identify the different B-cell populations: $\operatorname{lgM}^{+}$and $\lg \mathrm{M}^{-} \mathrm{CD} 27^{\text {bright }}$ plasma cells, $\mathrm{CD} 27^{+}$memory B cells that are either $\lg \mathrm{M}$ memory (IgM+) or switched memory (IgM), and mature B cells. The numbers indicate the percentages of these subpopulations in the B cell gate. (b) Each column represents the number of newly (black column), persistent (gray), and chronic (white) ITP patients that show a normal (Responders) or low response (Nonresponders) to CpG. (c) The histograms represent the concentration ( $\mu \mathrm{g} / \mathrm{ml}$ ) of IgM (white columns), IgA (gray), and IgG (black) immunoglobulins in the supernatants of 7-d cultures with CpG in healthy controls $(n=30)$ and ITP patients $(n=30)$. Patients are classified according to the stage of disease. (d) The histograms represent the frequency of total B cells and plasma cells of IgM or switched isotypes, in CpG-stimulated cultures from 30 controls (white columns) and 30 ITP patients (black columns). Statistical significance was determined by Student's $t$-test: ${ }^{*} P<0.01 ;{ }^{* *} P<0.0001$. CpG, cytosine-phosphate-guanine; ITP, immune thrombocytopenic purpura. 


\section{Articles $\mid$ Giordano etal.}

with ITP in childhood and splenectomized several years before our analysis. We have shown in previous studies that splenectomy is associated with an extreme reduction of the B-cell memory pool $(25,26)$. In contrast with these observations, in our splenectomized ITP patients, the frequency of memory B cells was in the normal range with a prevalence of switched memory B cells (Figure 4a).

By Enzyme-Linked ImmunoSpot Methods (ELISPOT), we measured the number of memory B cells able to generate antibody-producing cells in vitro after $\mathrm{CpG}$ stimulation. We first compared the number of spots generated by memory B cells of control adults with those produced by memory B cells of 37 age-matched splenectomized individuals without primitive disease affecting the immune system. As expected, the number of spots was significantly reduced in the splenectomized controls. In contrast, each of the splenectomized ITP patients generated more spots of each isotype in comparison not only to splenectomized adults but also to normal adult controls (Figure $4 \mathrm{~b}$ ). By ELISPOT, it is also possible to test the specificity of the antibody produced. Memory B cells against a vaccine antigen, such as tetanus, are mostly of $\operatorname{IgG}$ isotype. These were significantly reduced in splenectomized adults and also lower in the ITP patients when compared with controls. In contrast, IgM memory B cells producing antitetanus antibodies were lower in the splenectomized controls but not in ITP patients (Figure $5 \mathbf{a}, \mathbf{b}$ ).

Different results were obtained for pneumococcal polysaccharides. Pneumococcus is a common pathogen often colonizing the upper respiratory ways. Its polysaccharides represent the prototype $\mathrm{T}$-independent antigen. We have shown that the response to this type of antigens is primarily due to IgM memory B cells (23) a population that is usually depleted after splenectomy (25). The response also generates IgG and IgA. Splenectomized individuals have a significant reduction of antipneumococcus IgA and IgG spots (Figure 5c) and also of IgM spots (Figure 5d) (26). In splenectomized ITP patients, IgG and IgA were not reduced and IgM spots were increased as compared with controls and splenectomized adults. Thus, IgM memory B cells do not diminish after splenectomy in ITP patients with severe disease (Figure 5d).

\section{DISCUSSION}

Antibodies are molecules that, thanks to their ability to specifically recognize pathogens, cure infections and prevent relapses.

Autoimmune diseases are often characterized by the presence of antibodies that are not directed against foreign antigens and bind instead the one's own constituents. Antiplatelet antibodies cause ITP. The reasons leading to the production of autoantibodies remain mostly unknown. Animal models and human studies have identified several check points during B-cell development in the bone marrow and antigen-induced differentiation in the periphery, where induction of tolerance occurs purging the B-cell repertoire of dangerous specificities.

Although ITP has often a benign clinical course, in some cases, the reduced number of platelets remains a lifelong problem that cannot be solved by the available therapies. The various duration of disease and severity of clinical symptoms

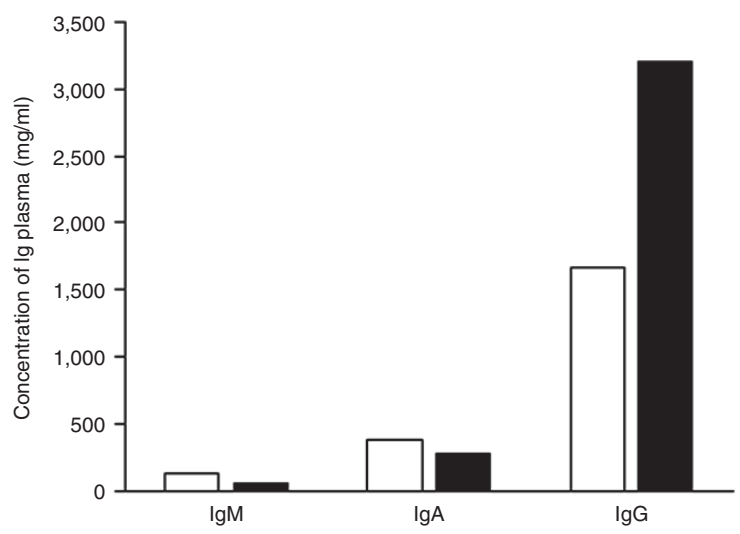

b

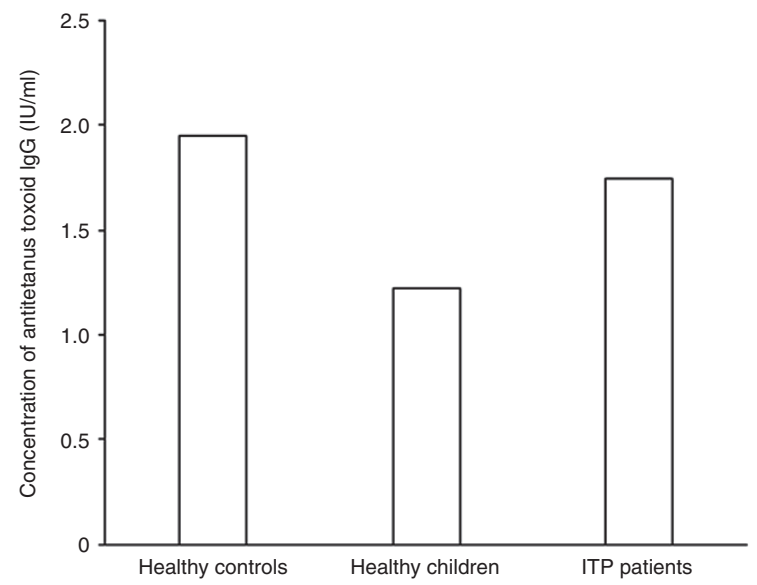

C

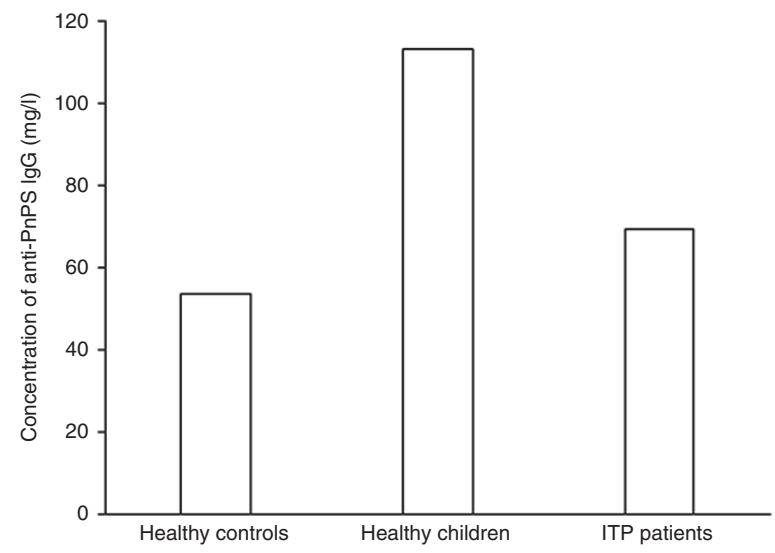

Figure 3. Total and specific serum antibodies concentration in healthy controls and ITP patients. (a) The histograms show the concentration (mg/dl) of total lgM, IgA, and lgG, in CTRL $(n=30)$ (white column) and ITP patients $(n=30)$ in the black column. (b) The antitetanus toxoid IgG serum concentration (IU/ml) in adult CTRL $(n=30)$, children CTRL $(n=30)$, and in ITP patients $(n=30)$ are shown. (c) The anti-PnPS IgG serum concentration (mg/l) in healthy CTRL $(n=30)$ healthy children $(n=30)$ and in ITP patients $(n=30)$ are shown. Statistical significance was determined by Student's $t$-test: ${ }^{*} P<0.01 ;{ }^{* *} P<0.0001$. ITP, immune thrombocytopenic purpura.

suggest that platelet destruction might be the common feature of ITP forms with different etiopathogenesis.

We found that B-cell function was altered in ITP, especially in the chronic forms. 
a

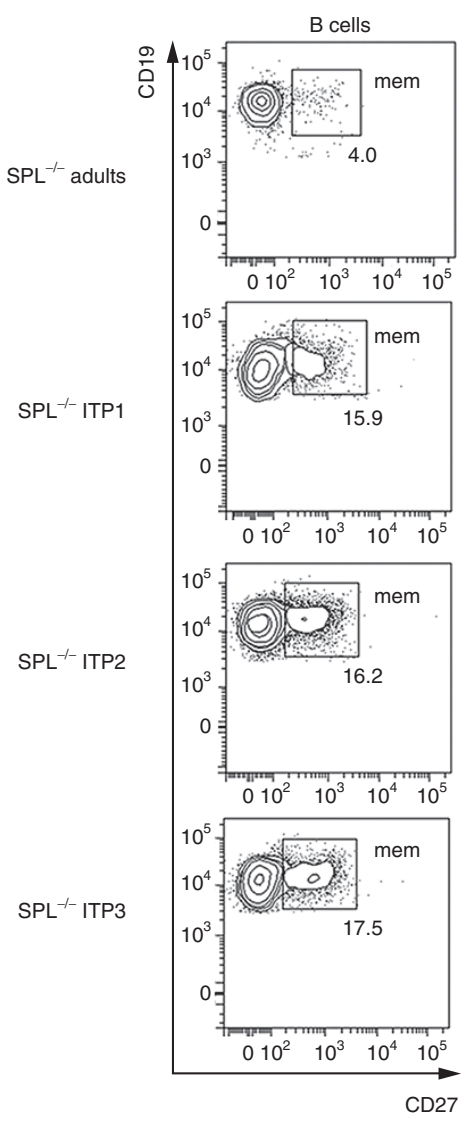

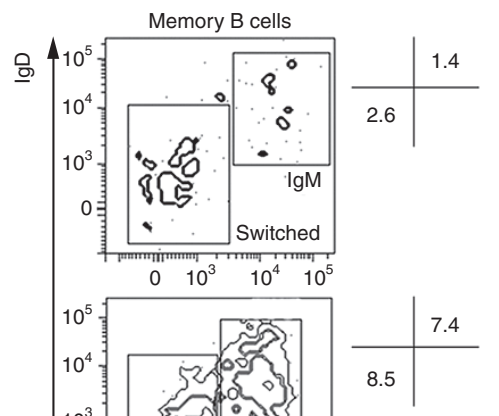

$10^{3}$

0 章

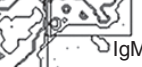

IgM

$\begin{array}{cccc}0 & 10^{3} & 10^{4} & 10^{5}\end{array}$

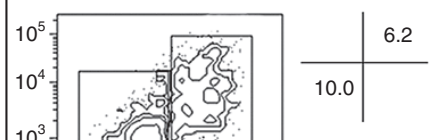

$10^{3}$

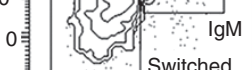

$010^{3} \cdot 10^{4} \cdot 10^{5}$

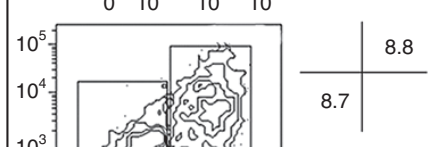

$10^{3}$

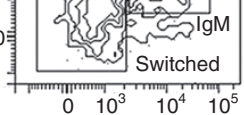

$0 \quad 10^{3} \quad 10^{4} \quad 10^{5}$

$\lg M$

b

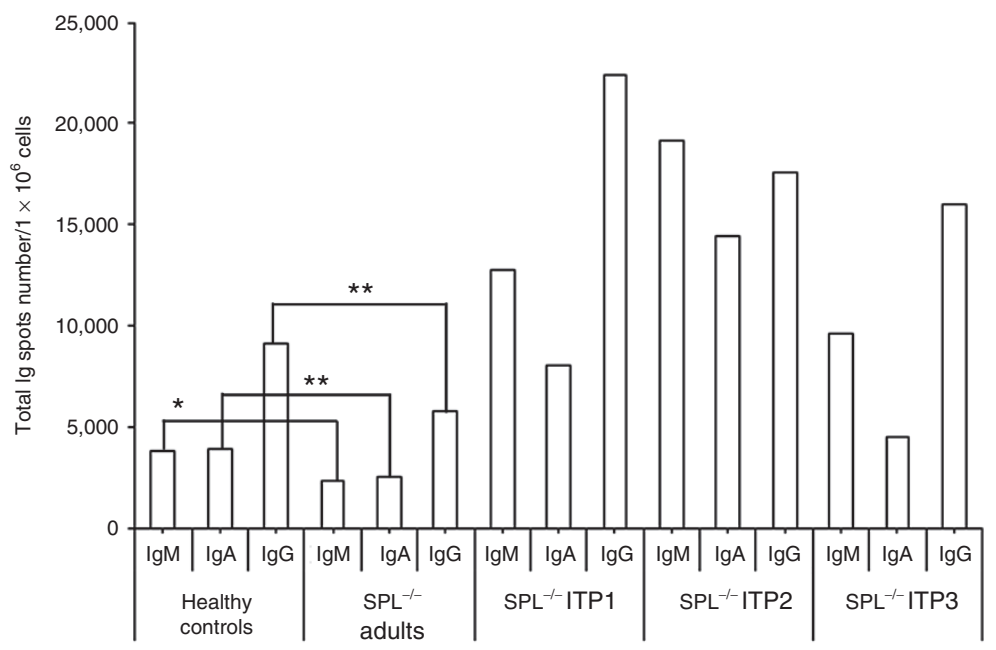

Figure 4. Memory B cells phenotype in the splenectomized ITP patients and their response to CpG. (a) Contour plots show the memory B cells $\left(C D 19^{+} \mathrm{CD} 27^{+}\right)$for representative splenectomized adult and three splenectomized ITP patients. The numbers indicate the percentage of total memory, switched, and IgM memory in the B cell gate. (b) The histograms represent the number of memory B cells secreting $\lg M$, IgA, and IgG after CpG stimulation in the peripheral blood of healthy controls $(n=30)$, splenectomized adults $(n=37)$, and splenectomized ITP patients $(n=3$, individually shown). Statistical significance was determined by Student's $t$-test: ${ }^{*} P<0.01 ;{ }^{* *} P<0.0001$. CpG, cytosine-phosphate-guanine; ITP, immune thrombocytopenic purpura.

Although B-cell numbers were comparable between patients and age-matched controls and B-cell populations were normally distributed (Figure 1), we found that ITP memory B cells showed an increased ability of generating plasma cells and secreted higher amounts of antibodies especially of $\operatorname{IgG}$ isotype in vitro (Figure 2).
The increased capacity of producing antibodies in vitro was correlated with a significantly higher level of IgG in the serum (Figure 3a).

In normal individuals, serum antibodies of $\operatorname{IgG}$ isotype are produced by long-lived plasma cells generated by previous immune responses and residing in the bone marrow (27-30). 
a

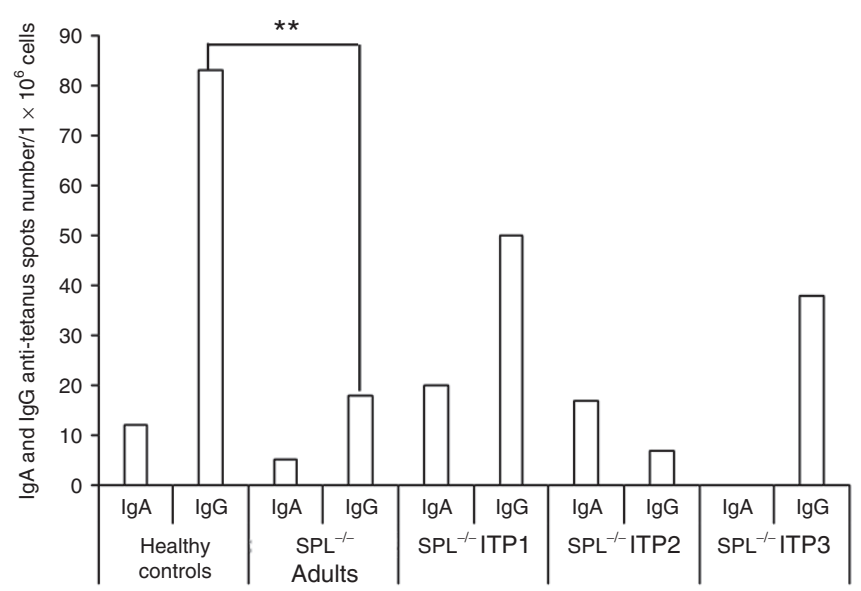

C

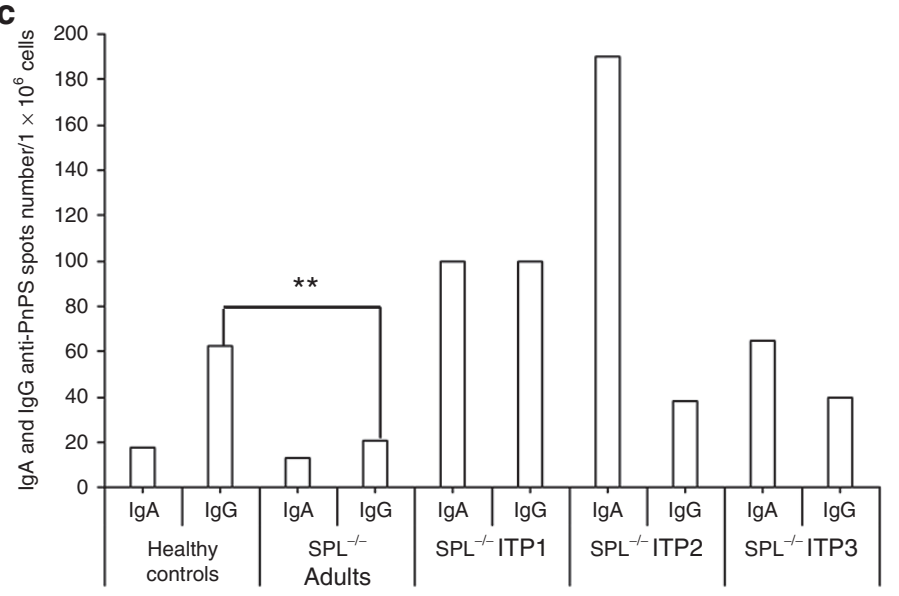

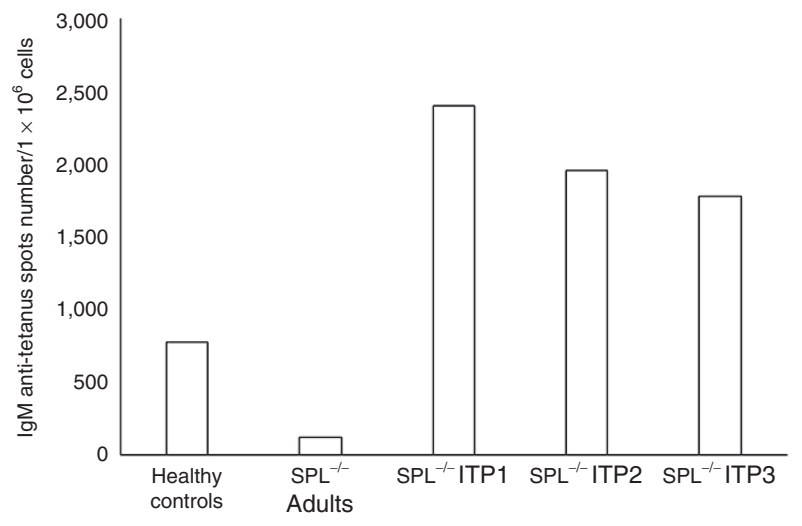

d

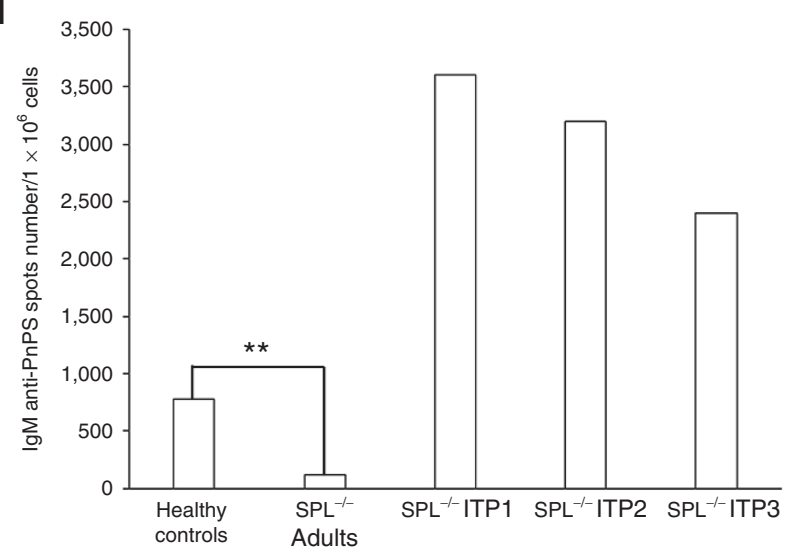

Figure 5. Number of memory $B$ cells secreting antibodies specific against tetanus toxoid and polysaccharides in the peripheral blood. The histograms show the number of memory B cells producing (a) IgA and IgG and (b) IgM against tetanus toxoid after stimulation with CpG from PBMC of 30 healthy controls (mean value), 37 splenectomized adults (mean value), and 3 splenectomized ITP patients. (c and $\mathbf{d}$ ) The number of memory B cells secreting anti-PnPS IgA and IgG, and IgM, directed against pneumococcal polysaccharides, respectively. Statistical significance was determined by Student's $t$-test: ${ }^{*} P<0.01 ;{ }^{* *} P<0.0001$. CpG, cytosine-phosphate-guanine; ITP, immune thrombocytopenic purpura; PBMC, peripheral blood mononuclear cell.

For example, antitetanus and antipneumococcal polysaccharide IgG antibodies in the serum are produced by this mechanism. The concentration of specific IgG was not increased in ITP patients (Figure $3 \mathbf{b}, \mathbf{c}$ ), suggesting that protective immunity is not altered in ITP.

Splenectomy is performed in ITP patients with the aim of sparing from destruction platelets tagged by autoantibodies. We have shown that the removal of the spleen causes depletion of both IgM and switched memory B cells (Figure 4a, right) $(25,26,31)$. The reduction of IgM memory B cells remains a permanent characteristic of splenectomized individuals, whereas switched memory B cells are slowly regenerated over time (31-33). We analyzed three ITP patients years after splenectomy. We found that in contrast to our observation in normal individuals, both IgM and switched memory B cells were present in these three patients (Figure 4a, right). Memory B cells were able to respond to $\mathrm{CpG}$ and generated a high number of antibody-producing cells detectable in ELISPOT. The number of spots was higher in splenectomized ITP than that in controls with or without spleen (Figure 4 b). We tested the specificity of memory B cells against two prototype antigens, tetanus toxin, which generates a T-dependent response, and pneumococcal polysaccharides, which are T-independent antigens (Figure 5). The frequency of B cells producing IgG and IgA against tetanus was reduced, whereas IgM antibody-producing cells were increased as compared with controls. For pneumococcus, IgG and IgA were not diminished, and IgM were higher than that in normal or splenectomized controls.

The question of how antibodies against platelets are produced is not solved. The idea of a mistake in tolerance induction during a normal germinal center response may explain the forms of disease that are cured by steroids and/or rituximab. Our results suggest that chronic ITP, relapsing after rituximab and splenectomy, might be associated with a constitutive B-cell defect leading to the T- and probably antigenindependent production of antibodies with different specificity including that against platelets. Our data are in agreement with the recent observation that proliferative lymphoid nodules containing B cells and follicular dendritic cells, but distinct from germinal centers, are found in the spleen of ITP patients. $\mathrm{T}$ cells were reduced, and BCL- 6 was not expressed in proliferative lymphoid nodules containing $B$ cells, suggesting that 
B-cell proliferation was driven by mechanisms different from those regulating physiological germinal center reactions (34). Dysregulation of B-cell function in ITP is also supported by the significant increase of the B-cell-activating factor in the serum of ITP patients $(35,36)$. B-cell-activating factor promotes B cell survival and antibody production (37) and is produced by different cell types including memory B cells stimulated with CpG (unpublished results).

In patients who develop treatment-resistant ITP, B-cell hyperfunction might cause relapse also after removal of the spleen.

Our data suggest that treatment-resistant chronic ITP may be caused by a constitutive B-cell hyperreactivity associated with increased formation of antibody-producing cells probably with different specificities including that against platelets. Further studies are necessary to elucidate this mechanism and develop novel therapeutic strategies.

\section{METHODS}

\section{Subjects}

Peripheral blood samples were obtained from 30 pediatric patients with ITP: of them, 7 were diagnosed as having newly diagnosed ITP (resolution within 3 mo from diagnosis), 3 persistent ITP (resolution between 3 and 12 mo from diagnosis), and 20 chronic ITP (thrombocytopenia lasting more than $12 \mathrm{mo}$ ). All patients were treated at the Pediatric Unit "F. Vecchio," Department of Biomedical Sciences and Human Oncology, University of Bari "Aldo Moro," and all were off therapy for at least $14 \mathrm{~d}$ at time of investigation.

Median age at diagnosis was 9 y (range: $2-17$ y); 17 were males and 13 females. The median platelet count at diagnosis was $89 \times 109 / 1$ (range: $18-300 \times 109 / 1$ ).

Twenty-eight patients had previously received one or more courses of intravenous immunoglobulin at standard doses $(0.8-1 \mathrm{~g} / \mathrm{kg} / \mathrm{d}$ for 1 or $2 \mathrm{~d}$ ), and corticosteroid (methylprednisolone $15-30 \mathrm{mg} / \mathrm{kg} / \mathrm{d}$ for 3 d) had also been given to 13 out of 30 cases. Four patients had been treated with rituximab $\left(375 \mathrm{mg} / \mathrm{m}^{2}\right.$ per dose i.v., 4 weekly doses $)$ and one with cyclosporin A ( $3 \mathrm{mg} / \mathrm{kg} / \mathrm{d}$ for $1 \mathrm{mo})$. Two patients had not received any therapy (none).

Additional demographic parameters, platelet count at the time of analysis, as well as past therapeutic regimen are shown in Table 1.

Three patients diagnosed with ITP in childhood (at 3, 9, and 15 $y$ of age) were splenectomized because of severe, treatment-resistant disease 12,4 , and 10 y before our analysis. At the time of our study, patient 1 had still very low platelet counts, the other two were in remission. Only patient 3 still had autoantibodies in the serum.

Age-matched children were used as controls. We compared B-cell numbers and function of ITP splenectomized patients to those of 37 age-matched individuals splenectomized for spherocytosis $(n=2)$, thalassemia $(n=19)$, trauma $(n=8)$, nonhematological tumors $(n=1)$, or other diseases $(n=7)$ and without primitive disease affecting the immune system.

Written, informed consent was obtained from the parents and from the adult patients. Blood samples $(10 \mathrm{ml})$ were collected at enrollment. This study was approved by the Ethical Committee of the PoliclinicoGiovanni XXIII in Bari (Italy).

\section{Cell Preparation and Flow Cytometric Analysis}

PBMCs were isolated by Ficoll Paque Plus (Amersham Pharmacia Biotech, Milan, Italy) density-gradient centrifugation. Lymphocytes were washed in phosphate-buffered saline (PBS) (1×) and stained with the appropriate combination of fluorochrome-conjugated antibodies to identify B-cell subsets: CD19, CD24, CD27, CD38, IgD (Becton Dickinson Bioscences, San Jose, CA), and IgM (Jackson ImmunoResearch Laboratories, West Grove, PA). Dead cells were excluded from the analysis by side/forward scatter gating. All analyses were performed on a FACSCanto II (Becton Dickinson,
Sunnyvale, CA) interfaced to a FACSDiva software (Becton Dickinson Bioscences). Fifty thousand gated events on living cells were analyzed, whenever possible, for each sample.

\section{Cell Cultures}

For polyclonal stimulation of memory B cells, $1-2 \times 10^{6}$ PBMCs were stimulated for $5 \mathrm{~d}$ in RPMI 1640 (InvivoGen, San Diego, CA) supplemented with $10 \%$ heat-inactivated fetal bovine serum (FBS; Hyclone Laboratories, Logan, UT), 2\% L-glutamine (Gibco BRL, Life Technologies, Monza, Italy), $5 \times 10^{-5} \mathrm{~mol} / \mathrm{l} 2$ - $\beta$ mercaptoethanol (Sigma, St Louis, MO) and $20 \mu \mathrm{g} / \mathrm{ml}$ gentamycin (Gibco BRL, Life Technologies), $2.5 \mu \mathrm{g} / \mathrm{ml} \mathrm{CpG-ODN} \mathrm{(Hycult} \mathrm{Biotechnology,} \mathrm{Uden,}$ The Netherlands), $20 \mathrm{ng} / \mathrm{ml}$ IL-21 (Peprotech, London, UK), and $20 \mathrm{ng} / \mathrm{ml} \mathrm{IL}-4$ (Peprotech).

\section{Proliferation Assay}

Before stimulation, PBMCs were labeled with 5-chloromethylfluorescein diacetate at a final concentration of $0.1 \mu \mathrm{g} / \mathrm{ml}$ (CellTracker; Molecular Probes, Life Technologies) and cultured at $5 \times 10^{5}$ cells per well in 96-well plates in complete RPMI 1640 (InvivoGen) supplemented with $10 \%$ fetal bovine serum (Hyclone Laboratories) in the presence or absence of $2.5 \mu \mathrm{g} / \mathrm{ml}$ of CpG oligodeoxynucleotide (ODN 2006; Hycult Biotechnology). Cell proliferation was measured on day 7 by flow cytometry.

\section{ELISA Immunoassay for $\lg M, \lg A$, and $\lg G$}

Plasma Igs and secreted Igs after stimulation with CpG were detected by ELISA. Briefly, 96-well plates (Corning, New York, NY) were coated overnight with purified antihuman IgA, IgG, and IgM (Jackson ImmunoResearch Laboratories). After washing with PBS/0.1\% Tween and blocking with $\mathrm{PBS} / 1 \%$ gelatin, plates were incubated for $1 \mathrm{~h}$ at 37 ${ }^{\circ} \mathrm{C}$ with either diluted plasma or culture supernatants. After washing, plates were incubated for $1 \mathrm{~h}\left(37^{\circ} \mathrm{C}\right)$ with peroxidase-conjugated goat antihuman IgA, IgG, or IgM Abs (Jackons ImmunoResearch Laboratories). The assay was developed with $o$-phenylen-diamine tablets (Sigma-Aldrich) as a chromogene substrate. Adsorbance at $450 \mathrm{~nm}$ was measured, and Ig concentrations were calculated by interpolation from the standard curve.

\section{ELISA for Antitetanus Toxoid and Anti-PnPS IgG}

Specific antitetanus toxin and anti-PnPS IgG serum concentrations were measured using VaccZyme Anti-Tetanus Toxoid IgG Enzyme Immunoassay kit and VaccZyme Anti-PCP IgG Enzyme Immunoassay kit from Binding Site (The Binding Site, Grassobio, Italy) respectively, according to the manufacturer's instructions. For anti-PnPS, IgG concentrations were calculated from the standard curves in $\mathrm{mg} / \mathrm{l}$ and converted into $\mathrm{IU} / \mathrm{ml}(1 \mathrm{IU} / \mathrm{ml}=17 \mathrm{mg} / \mathrm{l})$. Protective $\mathrm{IgG}$ serum levels for tetanus are $0.01-0.15 \mathrm{IU} / \mathrm{ml}$.

\section{Enzyme-Linked ImmunoSpot Methods}

96-well plates (Multiscreen-HA; Merk Millipore, Billerica, MA) were coated overnight with ether AffiniPure $\mathrm{F}\left(\mathrm{ab} \mathrm{b}^{\prime}\right)$, fragment, goat antihuman $\operatorname{Ig} \mathrm{A}+\operatorname{IgG}+\operatorname{IgM}(\mathrm{H}+\mathrm{L})$ (Jackson Immunoresearch Laboratories), or synthetic tetanus toxin peptide (C-term) (Acrisantibodies, Herford, Germany) or PneumoVax (Sanofi Pasteur MSD, Rome, Italy) containing S. pneumoniae polysaccharides of the following serotypes $1,2,3,4,5,6 \mathrm{~B}, 7 \mathrm{~F}, 8,9 \mathrm{~N}, 9 \mathrm{~V}, 10 \mathrm{~A}, 11 \mathrm{~A}$, $12 \mathrm{~F}, 14,15 \mathrm{~B}, 17 \mathrm{~F}, 18 \mathrm{C}, 19 \mathrm{~F}, 19 \mathrm{~A}, 20,22 \mathrm{~F}, 23 \mathrm{~F}$, and 33F. After washing with sterile PBS/0.05\% Tween-20, plates were blocked for $1 \mathrm{~h}$ at $37{ }^{\circ} \mathrm{C}$ with $\mathrm{PBS} / 1 \%$ gelatin. PBMCs were stimulated for $5 \mathrm{~d}$, as described earlier, were collected, counted, and seeded in the precoated plates. Plates were left at $37{ }^{\circ} \mathrm{C}, 2 \% \mathrm{CO}_{\text {, for }} 4-6 \mathrm{~h}$ to allow antibody secretion. Each sample was analyzed at three consecutive serial dilutions starting with $5 \times 10^{4}$ cells for detection of total IgG. Plates were washed with $\mathrm{ddH}_{2} \mathrm{O} / 0.05 \%$ Tween 20 (once) and PBS/0.05\% Tween20 (twice) and incubated overnight with antiIgG HRPO (1:2,000) (Jackson Immunoresearch Laboratories) diluted in $\mathrm{PBS} / 1 \%$ gelatin $+0.05 \%$ Tween 20 (Sigma). After washing twice with PBS/0.05\% Tween20, TMB substrate (ready to use from Mabtech-ELISpot plus for human IgG kit, Mabtech AB, Nacka Stround, Sweden) was used according to the manufacturer's instruction. Plates were left at room temperature to allow the blue color to develop, and the reaction was stopped with $\mathrm{ddH}_{2} 0$. Plates were left 
to dry before counting. Antibody-secreting cell counting was performed by two blinded independent operators.

\section{Statistical Analysis}

Data were analyzed using the StatView statistical program for MacIntosh (SatView Software, San Diego, CA), and significance determined with the paired Student's $t$-test. $P$ values less than 0.05 were considered to be statistically significant.

\section{STATEMENT OF FINANCIAL SUPPORT}

No financial assistance was received to support this study.

Disclosure: The authors declare no conflict of interest

\section{REFERENCES}

1. Glanz J, France E, Xu S, Hayes T, Hambidge S. A population-based, multisite cohort study of the predictors of chronic idiopathic thrombocytopenic purpura in children. Pediatrics 2008;121:e506-12.

2. Rodeghiero F, Stasi R, Gernsheimer T, et al. Standardization of terminology, definitions and outcome criteria in immune thrombocytopenic purpura of adults and children: report from an international working group. Blood 2009;113:2386-93.

3. Kühne T, Imbach P, Bolton-Maggs $\mathrm{PH}$, Berchtold W, Blanchette V, Buchanan GR; Intercontinental Childhood ITP Study Group. Newly diagnosed idiopathic thrombocytopenic purpura in childhood: an observational study. Lancet 2001;358:2122-5.

4. Giordano P, Lassandro G, Giona F, et al. ITP-QoL questionnaire for children with immune thrombocytopenia: Italian version validation's. Pediatr Hematol Oncol 2014;31:534-47.

5. Stasi R, Evangelista ML, Stipa E, Buccisano F, Venditti A, Amadori S. Idiopathic thrombocytopenic purpura: current concepts in pathophysiology and management. Thromb Haemost 2008;99:4-13.

6. De Mattia D, Del Principe D, Del Vecchio GC, et al. Acute childhood idiopathic thrombocytopenic purpura: AIEOP consensus guidelines for diagnosis and treatment. Associazione Italiana di Ematologia e Oncologia Pediatrica. Haematologica 2000;85:420-4.

7. De Mattia D, Del Vecchio GC, Russo G, et al.; AIEOP-ITP Study Group. Management of chronic childhood immune thrombocytopenic purpura: AIEOP consensus guidelines. Acta Haematol 2010;123:96-109.

8. Yang R, Han ZC. Pathogenesis and management of chronic idiopathic thrombocytopenic purpura: an update. Int J Hematol 2000;71:18-24.

9. Imbach P, Kühne T, Müller D, et al. Childhood ITP: 12 months follow-up data from the prospective registry I of the Intercontinental Childhood ITP Study Group (ICIS). Pediatr Blood Cancer 2006;46:351-6.

10. Benesch M, Kerbl R, Lackner H, et al. Low-dose versus high-dose immunoglobulin for primary treatment of acute immune thrombocytopenic purpura in children: results of a prospective, randomized single-center trial. J Pediatr Hematol Oncol 2003;25:797-800.

11. Carcao MD, Zipursky A, Butchart S, Leaker M, Blanchette VS. Short-course oral prednisone therapy in children presenting with acute immune thrombocytopenic purpura (ITP). Acta Paediatr Suppl 1998;424:71-4.

12. Aronis S, Platokouki H, Avgeri M, Pergantou H, Keramidas D. Retrospective evaluation of long-term efficacy and safety of splenectomy in chronic idiopathic thrombocytopenic purpura in children. Acta Paediatr 2004;93:638-42.

13. D'Orazio JA, Neely J, Farhoudi N. ITP in children: pathophysiology and current treatment approaches. J Pediatr Hematol Oncol 2013;35:1-13.

14. Sarpatwari A, Provan D, Erqou S, Sobnack R, David Tai FW, Newland AC. Autologous 111 In-labelled platelet sequestration studies in patients with primary immune thrombocytopenia (ITP) prior to splenectomy: a report from the United Kingdom ITP Registry. Br J Haematol 2010;151:477-87.

15. Olsson B, Andersson PO, Jernås M, et al. T-cell-mediated cytotoxicity toward platelets in chronic idiopathic thrombocytopenic purpura. Nat Med 2003;9:1123-4.
16. Provan D, Stasi R, Newland AC, et al. International consensus report on the investigation and management of primary immune thrombocytopenia. Blood 2010;115:168-86.

17. Semple JW, Provan D. The immunopathogenesis of immune thrombocytopenia: T cells still take center-stage. Curr Opin Hematol 2012;19: $357-62$.

18. George JN. Management of immune thrombocytopenia-something old, something new. N Engl J Med 2010;363:1959-61.

19. Patel VL, Mahévas M, Lee SY, et al. Outcomes 5 years after response to rituximab therapy in children and adults with immune thrombocytopenia. Blood 2012;119:5989-95.

20. Audia S, Samson M, Guy J, et al. Immunologic effects of rituximab on the human spleen in immune thrombocytopenia. Blood 2011;118: 4394-400.

21. Mahévas M, Patin P, Huetz F, et al. B cell depletion in immune thrombocytopenia reveals splenic long-lived plasma cells. J Clin Invest 2013;123: $432-42$.

22. Capolunghi F, Rosado MM, Cascioli S, et al. Pharmacological inhibition of TLR9 activation blocks autoantibody production in human B cells from SLE patients. Rheumatology (Oxford) 2010;49:2281-9.

23. Capolunghi F, Cascioli S, Giorda E, et al. CpG drives human transitional $\mathrm{B}$ cells to terminal differentiation and production of natural antibodies. J Immunol 2008;180:800-8.

24. Bernasconi NL, Traggiai E, Lanzavecchia A. Maintenance of serological memory by polyclonal activation of human memory B cells. Science 2002;298:2199-202.

25. Kruetzmann S, Rosado MM, Weber H, et al. Human immunoglobulin M memory B cells controlling Streptococcus pneumoniae infections are generated in the spleen. J Exp Med 2003;197:939-45.

26. Rosado MM, Gesualdo F, Marcellini V, et al. Preserved antibody levels and loss of memory B cells against pneumococcus and tetanus after splenectomy: tailoring better vaccination strategies. Eur J Immunol 2013;43: 2659-70.

27. Manz RA, Löhning M, Cassese G, Thiel A, Radbruch A. Survival of long-lived plasma cells is independent of antigen. Int Immunol 1998;10: 1703-11.

28. Manz RA, Thiel A, Radbruch A. Lifetime of plasma cells in the bone marrow. Nature 1997;388:133-4.

29. Tarlinton D, Radbruch A, Hiepe F, Dörner T. Plasma cell differentiation and survival. Curr Opin Immunol 2008;20:162-9.

30. Yoshida T, Mei H, Dörner T, et al. Memory B and memory plasma cells. Immunol Rev 2010;237:117-39.

31. Di Sabatino A, Carsetti R, Corazza GR. Post-splenectomy and hyposplenic states. Lancet 2011;378:86-97.

32. Capolunghi F, Rosado MM, Sinibaldi M, Aranburu A, Carsetti R. Why do we need IgM memory B cells? Immunol Lett 2013;152:114-20.

33. Aranburu A, Ceccarelli S, Giorda E, Lasorella R, Ballatore G, Carsetti R. TLR ligation triggers somatic hypermutation in transitional B cells inducing the generation of IgM memory B cells. J Immunol 2010;185: 7293-301.

34. Daridon C, Loddenkemper C, Spieckermann S, et al. Splenic proliferative lymphoid nodules distinct from germinal centers are sites of autoantigen stimulation in immune thrombocytopenia. Blood 2012;120: 5021-31.

35. McKenzie CG, Guo L, Freedman J, Semple JW. Cellular immune dysfunction in immune thrombocytopenia (ITP). Br J Haematol 2013;163: $10-23$.

36. Emmerich F, Bal G, Barakat A, et al. High-level serum B-cell activating factor and promoter polymorphisms in patients with idiopathic thrombocytopenic purpura. Br J Haematol 2007;136:309-14.

37. Figgett WA, Vincent FB, Saulep-Easton D, Mackay F. Roles of ligands from the TNF superfamily in B cell development, function, and regulation. Semin Immunol 2014;26:191-202. 